made him a devoted student of geology and palæontology ; Raphael Pumpelly (1837-1923) turned geologist on coming under the influence of Noeggerath at Freiburg, and so embraced a profession which brought him a life full of adventure in many lands, while Thomas Davies (1837-93), who edited the Mineralogical Magazine, followed in the footsteps of his father William Davies (1814-91) when in 1858 he entered the service of the British Museum. Among metallurgists, few in his day were known better than George James Snelus (1837-1906), who for his work on the elimination of phosphorus from molten pig iron, received in 1883 one Bessemer Gold Medal, while another was given to Sidney Thomas. In Germany, no man did more to establish the engineering industry on a sound basis than Ludwig Loewe (1837-86), the founder of a still famous firm, while American invention and engineering are recalled by the names of Robert McAlpine (1837-1911), a pioneer in the manufacture of paper from ground wood pulp, and Colonel Washington Augustus Roebling (1837-1926), to whom fell the task of constructing the Brooklyn Bridge at New York.

\title{
The Iguanodons in the Brussels Museum
}

$\mathrm{W}^{\mathrm{B}}$ are glad to record that the unique collection of skeletons of the Wealden dinosaur Iguanodon in the Royal Museum of Natural History at Brussels has now been installed for safe preservation in two air-tight glass cases, which are probably the largest exhibition cases hitherto placed in a museum. The twelve skeletons, which are mounted in their natural position on iron framework, occupy a case which measures 18 metres in length, 11 metres in maximum width, and 7 metres in height. Part of it is shown in the accompanying photograph (Fig. 1). The skeletons which still lie attached to masses of rock are covered with a case measuring 20.5 metres in length, 13 metres in width, and 7 metres in height. The cases were made by the Belgian branch of the English firm, Messrs. Fred. Sage and Co. Ltd., which has supplied cases to the British Museum and to other English museums.

When these fossil bones were first extracted from the rock and prepared for study between 1878 and 1900, they were hardened with an aqueous solution of gelatine. The treatment, however, proved to be insufficient to prevent the decay of the iron pyrites with which most of the specimens were permeated, and a few years ago it became evident that the collection could only be preserved by some other method of hardening the bones and by protecting them in future from contact with more or less damp air.
To devise a new treatment was difficult, because much of the gelatine still remained in the fossils and prevented the absorption of any other material. Experiments were therefore made, and it was decided to remove the gelatine so far as possible

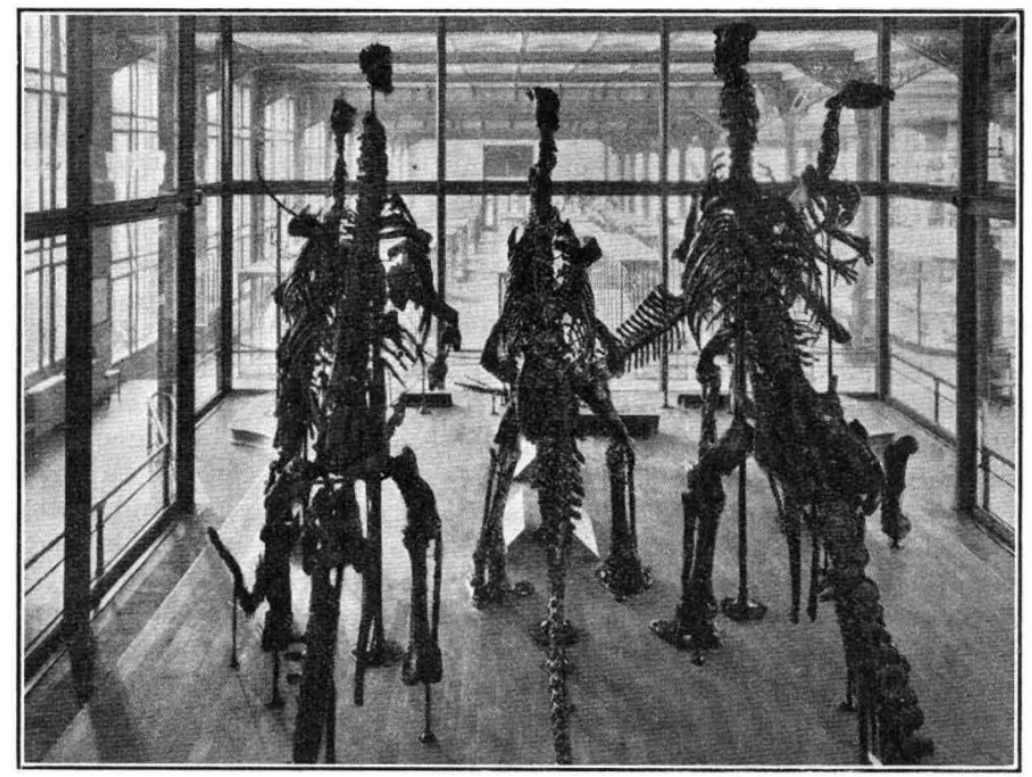

Fig. 1.

Iguanodons in the Royal Museum of Natural History, Britssels. Photo by E. Sergysels, Brux.

and replace it with shellac to be deposited from a solution in alcohol. The bones were washed with tepid soapy water to which a little carbonate of soda had been added, and after each washing they were rinsed with tepid water and carefully dried in a heated chamber. Immediately after drying, and while still at a temperature of $45^{\circ} \mathrm{C}$., they were placed for twenty-four hours or more, 
according to size, in a bath containing shellac dissolved in alcohol, one part of shellac to three parts of alcohol at $94^{\circ} \mathrm{C}$. When the bones were taken out of the bath they were washed with alcohol to remove the excess of shellac, and then they were left to dry in a current of air at the ordinary temperature while the solution completely impregnated them. The process was repeated once, and the bones were then ready for the preparators, who mended cracks and other deficiencies. Finally, a weaker solution of shellac, one part to four parts of alcohol, was driven by a compressed-air syringe into the surface of the bones, and they were again left to dry. This process was repeated three times, and the specimens were then re-mounted on their supports.

All the mounted skeletons of Iguanodon are now complete, and it is anticipated that all the bones exposed in the rock masses will be treated before the end of this year. The skeletons of the associated fossil crocodiles, Goniopholis and Bernissartia, will then be preserved from decay in the same manner. The Belgian Government and Dr. V. Van Straelen, the director of the Brussels Museum, and his staff, are to be congratulated on their success in an important scientific undertaking. A. S. W.

\section{Obituary Notices}

Sir Herbert Jackson, K.B.E., F.R.S.

CIR HERBERT JACKSON, whose death occurred $S$ on December 10 after a very brief illness, was born on March 17, 1863. After attending King's College School, he entered King's College, London, in 1879 as a special student of chemistry, and for a number of years he worked both as student and student-demonstrator in Prof. C. L. Bloxam's private laboratory. His association with King's College continued without interruption until 1918. He held successively the positions of lecturer, assistant professor (1902), and professor of organic chemistry (1905); he was elected a fellow of King's College in 1907, and was finally appointed Daniell professor of chemistry on the retirement of Prof. John Millar Thomson in 1914. He was regarded with affection by all the students of the College for the zest with which he participated in their social and athletic activities, which affection was enhanced among those who studied under him by their recognition of his admirable teaching capabilities.

During this period, Sir Herbert Jackson's research activities covered an extraordinarily wide range. He carried out a lengthy investigation into the production of phosphorescent materials, and made an extensive study of the phosphorescent and fluorescent phenomena produced in various materials by ultra-violet light or by electric discharge in low-vacuum and highvacuum discharge tubes. In the course of his experiments with high-vacuum tubes he observed that in some instances phosphorescent materials in close proximity to the tubes gave a luminous response when the tubes were excited. This observation was not followed up immediately as it did not fall into the general line of investigation which was being pursued at the time, otherwise the discovery of X-rays, which was announced by Röntgen a few months later, might well have been made by Sir Herbert Jackson. Immediately Röntgen's discovery was published, Sir Herbert Jackson constructed an $\mathrm{X}$-ray tube of the type described by Röntgen-the first X-ray tube to be produced in Great Britain- and thereafter he devoted a considerable amount of attention to a study of the effects which could be produced by the 'new' rays and to the development of X-ray tubes of improved forms. The 'Jackson' focus-tube, which he devised-and which he refused to patent-was a development of very great importance, since it provided practically a point source of $X$-rays and thus ensured sharp definition in X-ray photographs; the curved cathode which was its essential feature was adopted universally.

It is impossible to give any complete account of the many lines of investigation which Sir Herbert Jackson pursued while he was at King's College, but by way of contrast to the foregoing, mention may perhaps be made of two other items. He made a considerable study of the detergent action of alkalis, oils, soaps and chemical solvents, and of their behaviour on fabrics of different types. His work in this direction and the lectures and demonstrations which he gave to special classes for launderers are gratefully remembered by the laundry industry as a whole for their immense practical value. Sir Herbert also brought his scientific knowledge to bear on methods of protecting stonework against weathering action, and for many years devoted a good deal of attention to this important problem.

Sir Herbert Jackson was recognized as a microscopist of the first rank. In the widely varied types of scientific work which he had undertaken he had made very considerable use of his microscope, and he was, in consequence, familiar with the appearances presented under all available types of illumination, by bacilli, crystals, diatoms, fibres, gratings, powders, rulings, metals and all the more usual microscopic objects. He had also made a considerable study of the microstructure of porcelains, glazes, opal and coloured glasses, etc., and his observations, backed by his chemical knowledge, enabled him to draw important and far-reaching conclusions relating to the methods which had been employed in the production of Chinese and other ceramic wares, ancient 